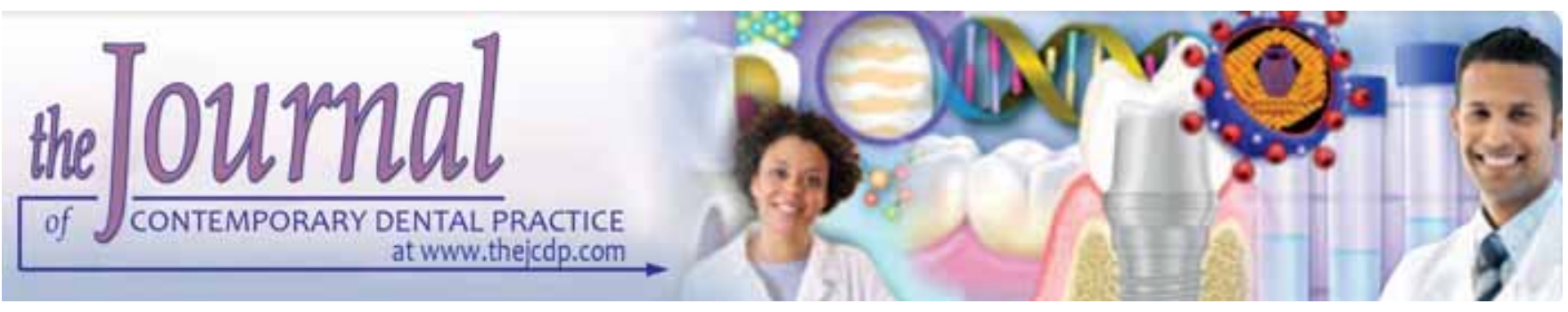

\title{
Apical Force Distribution due to Orthodontic Forces: A Finite Element Study
}

\author{
Anirudh K Mathur, Vikas Gupta, Anirban Sarmah, Vinaya S Pai, G Chandrashekar
}

\section{ABSTRACT}

Aim: This finite element study was conducted to calculate the distribution of stresses in the periodontal ligament when various orthodontic forces were applied, with emphasis on the effect on root apex.

Materials and methods: An in vitro finite element method was used to construct a three-dimensional finite element model of a maxillary central incisor, its periodontal ligament and alveolar bone was constructed on the basis of average anatomic morphology. To this model, five types of orthodontic forces namely tipping, bodily movement, intrusion, extrusion and rotations were applied at various points on the crown of the tooth model. After the application of the forces, initial stress and initial displacements of the periodontal ligament were evaluated. The principal stress obtained on the periodontal ligament due to various orthodontic loadings on the maxillary central incisor was analyzed using ANSYS 10 finite element software.

Results: It showed that the greatest amount of relative stress at the apex of maxillary central incisor occurred with intrusion, extrusion and rotation. Bodily movement and tipping forces produce stress concentrated at the alveolar crest and not at the root apex.

Conclusion: Clinical implications of this study suggest that if the clinician is concerned about placing heavy stresses on the root apex, then vertical and rotational forces must be applied with caution.

Clinical Significance: If heavy stresses are to be placed on the root apex, then vertical and rotational forces must be applied with caution during orthodontic therapy.

Keywords: Periodontium, Stress, Mechanical forces, Finite element method.

How to cite this article: Mathur AK, Gupta V, Sarmah A, Pai VS, Chandrashekar G. Apical Force Distribution due to Orthodontic Forces: A Finite Element Study. J Contemp Dent Pract 2011;12(2):104-108.

Source of support: Nil

Conflict of interest: None declared

\section{INTRODUCTION}

It is now nearly 2000 years since the phenomenon of tooth movement in response to an applied load was first reported (Celcus, 1st century AD). Currently although the teeth are moved routinely in orthodontic practice, there is still a lot of uncertainty about the exact ongoing changes in biomechanical loading of tissues and the precise mechanisms of tissue response following the force application to the crown of the tooth. ${ }^{1}$ Once force is applied to the tooth, stress is distributed instantly along the periodontal ligament to achieve a state of equilibrium. ${ }^{2}$ The quantification of the stress in the periodontal ligament is an important concept as stress in this tissue is transmitted to alveolus with subsequent bone remodeling and tooth movement. ${ }^{3}$ The application of external forces to the teeth to produce orthodontic tooth movement carries some calculated risks one of which is irreversible root resorption. Different types of orthodontic tooth movement may produce different mechanical stress at varying locations within the root. ${ }^{4}$ External root resorption presents a paradox while known to be commonly occurring as an inflammatory reaction to tooth movement. Severe resorption requires clinical alteration of treatment or in the worst scenario even loss of teeth. ${ }^{5}$ It is important to gain an improved biomechanical understanding of what occurs further up the chain of events immediately after the application of load on the tooth crown. ${ }^{1}$

In orthodontics, many attempts have been made to model the reactions of teeth and their supporting tissues on application of orthodontic forces. ${ }^{6}$ One of these methods is finite element method. The finite element method is a highly precise technique used to analyze structural stress. It has been used in civil and aerospace engineering for years. This method uses computers to solve large number of equations to calculate stress on the basis of physical properties and the structures being analyzed. It has many advantages over 
other methods. It is highlighted by the ability to include heterogeneity of the tooth material and irregularity of the tooth contour and relative ease with which loads can be applied at different directions and magnitude for complete analysis. ${ }^{4}$ This method offers accurate modeling of tooth and its surrounding structures with its complicated geometry. It makes it possible to analytically apply various forces at any point, in any direction and also quantitatively and qualitatively assess the distribution of such forces through the alveolar bone, periodontal ligament and tooth. ${ }^{1}$ Hence, finite element method was chosen in this study to calculate the stress pattern in periodontal ligament due to various orthodontic forces with emphasis on stress distribution at the root apex at the maxillary central incisor.

\section{MATERIALS AND METHODS}

In this study, a three-dimensional finite element model of permanent maxillary central incisor and its supporting structures was generated and used to analyze the stress generated and distributed due to various orthodontic tooth movements.

\section{Finite Element Model}

Finite element modeling is the representation of geometry in terms of a finite number of elements and their connection points known as nodes. These are the building blocks of numerical representation of the model. The 'elements' present are of finite number as opposed to a theoretical model with complete continuity. The object of interest has to be broken up into a 'meshwork' that consists of a number of nodes on and in the object. These nodes or points are then connected to form a system of elements. By knowing the mechanical properties of the object, such as modulus of elasticity and Poisson's ratio, one can determine how much distortion each part of the cube undergoes when other part is moved by a force.

In this study, the analytical model of maxillary central incisor was developed according to dimensions and morphology found in a standard textbook of Dental Anatomy, Physiology and Occlusion by Wheeler's. ${ }^{8}$ Periodontal ligament was simulated as a $0.25 \mathrm{~mm}$ thick ring around the model of the tooth ${ }^{6}$ according to previous studies. The finite element model generation was achieved with the help of ANSYS 10 software. The element shape which was described in the model was a solid 10 noded tetrahedral with 3 degree of freedom. The finite element model approximately consisted of 2,04,760 elements and 35,702 nodes (Fig. 1). Each structure was then assigned a specific material property. The different structures in the finite element model are enamel, dentine, periodontal ligament and alveolar bone. The material properties used in this study have been taken from finite element studies previously

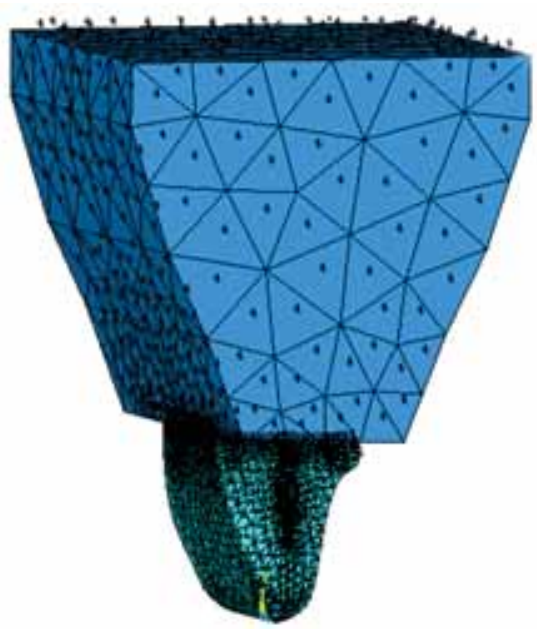

Fig. 1: Finite element model of the tooth

conducted. These material properties were the average values reported in the literature ${ }^{4}$ (Table 1 ). In this tissue, all the structures were assumed to be isotropic.

\begin{tabular}{lcc}
\multicolumn{3}{c}{ Table 1: Material parameters used in the finite element model } \\
\hline Material & $\begin{array}{c}\text { Young's modulus } \\
\left(\mathrm{N} / \mathrm{mm}^{2}\right)\end{array}$ & Poisson's ratio \\
\hline Enamel & $8.41 \times 10^{4}$ & 0.3 \\
Dentin & $1.83 \times 10^{4}$ & 0.30 \\
Periodontal ligament & $6.90 \times 10^{-1}$ & 0.45 \\
Bone & $1.37 \times 10^{4}$ & 0.30 \\
\hline
\end{tabular}

\section{Application of Forces}

The loading configuration was designed to simulate conventional orthodontic tooth movement. Application of forces in this study was in conjunction with the range of optimum forces for orthodontic tooth movement proposed by Proffit $^{9}$ (Table 2).

Intrusion: A 10 gm of vertical force parallel to the long axis of the tooth was applied on the labial surface at the midpoint of the crown, which coincides with the base of the bracket slot.

Extrusion: A 35 gm of vertical force parallel to the long axis of the tooth was applied on the labial surface at the midpoint of the crown, which coincides with the base of the bracket slot.

Tipping: A force of $35 \mathrm{gm}$ in labiolingual direction perpendicular to the long axis of the tooth was applied on the labial surface at the midpoint of the crown, which coincides with the base of the bracket slot.

Rotation: Thirty-five grams of horizontally directed forces were applied in opposite directions along the line angles at the midpoint of the margins of the crown. One force was labiolingually directed and the other force was linguolabially directed. 
Table 2: Force system applied

\begin{tabular}{lcl}
\hline Force type & Force magnitude $(\mathrm{gm})$ & \multicolumn{1}{c}{ Direction } \\
\hline Intrusion & $10 \mathrm{gm}$ & Intrusion force acting parallel to the long axis of tooth from center of the crown \\
Extrusion & $35 \mathrm{gm}$ & Extrusion force acting parallel to long axis of tooth from center of the crown \\
Rotation & $35 \mathrm{gm}$ & Horizontal force along the line angles of the incisor in opposite directions \\
Tipping & $35 \mathrm{gm}$ & Horizontal force in a lingual direction applied perpendicular to long axis of the tooth \\
Bodily movement & $70 \mathrm{gm}$ & Horizontal force in a lingual direction with a couple in a buccal crown direction \\
\hline
\end{tabular}

Bodily movement: To apply bodily movement, it is necessary to apply a couple to create a moment (the moment of a couple or $\mathrm{Mc}$ ) equal in magnitude and opposite in direction to the original movement. A pair of forces of equal magnitude of $70 \mathrm{gm}$ were applied perpendicular to the long axis of the tooth. One force was applied in buccolingual direction at the midpoint of the crown, which coincides with the point where bracket base is located. The other force of equal magnitude was linguobuccally directed and applied at the incisal tip.

The stress calculated for these orthodontic loadings is principle stress and these stresses are expressed as compressive stress (which are negative) or tensile stress (which are positive).

\section{RESULTS}

Intrusion: When $10 \mathrm{gm}$ of intrusive force was applied parallel to long axis of the tooth on the labial surface at the midpoint of the crown, it produced compressive stress as high as $-0.004497 \mathrm{~N} / \mathrm{mm}^{2}$ at the apex of the PDL and tensile stress as high as $0.004177 \mathrm{~N} / \mathrm{mm}^{2}$ on the labial surface of the PDL near the apical region and cervical margin on the lingual surface (Fig. 2). The stress was found to be mainly concentrated at the apex. The stress found at the apical region was $-0.004497 \mathrm{~N} / \mathrm{mm}^{2}$. It was mainly compressive in nature. These values were seen as the force applied was on the labial surface of the crown and not along the center of resistance coinciding with long axis of the tooth.

Extrusion: When 35 gm of extrusive force was applied parallel to the long axis of the tooth on the labial surface at the midpoint of the crown, it produces tensile stress as high as $0.028818 \mathrm{~N} / \mathrm{mm}^{2}$ at the apex of the PDL and compressive
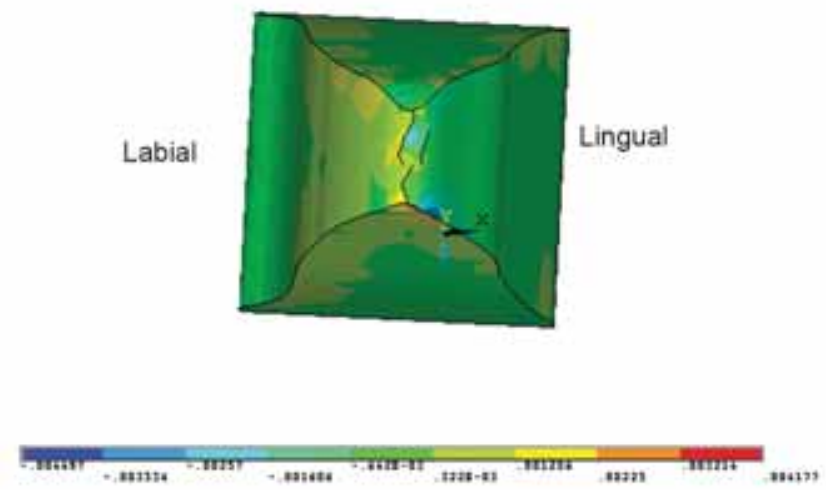

Fig. 2: Stress distribution in PDL during intrusion stress as high as $-0.007235 \mathrm{~N} / \mathrm{mm}^{2}$ is seen at the cervical margin on the lingual side (Fig. 3).

The stress was found to be mainly concentrated at the apical region. The stress at the apical region was $0.028818 \mathrm{~N} / \mathrm{mm}^{2}$. It was mainly tensile in nature. The stress seen was not totally tensile in nature, compressive stress was also seen as the point of force application was on the labial surface of the crown and not along the center of resistance coinciding with the long axis of the tooth.

Rotation: When 35 gm of horizontally directed forces were applied in opposite directions along the line angles of the crown, the stress was distributed along the periodontal ligament with a general lack of any specific area of excessive stress. The compressive stress as high as $-0.029402 \mathrm{~N} / \mathrm{mm}^{2}$ was seen at the apical region and cervical margin. Tensile stress as high as $0.047697 \mathrm{~N} / \mathrm{mm}^{2}$ was seen at the apical region and cervical margin (Fig. 5). The apical region showed stress of $-0.029402 \mathrm{~N} / \mathrm{mm}^{2}$.

Tipping: When 35 gm of tipping force was applied perpendicular to long axis of the teeth on the labial surface at the midpoint of the crown, it produced compressive stress as high as $-0.018476 \mathrm{~N} / \mathrm{mm}^{2}$ at the cervical margin on the lingual side and tensile stress was $0.030849 \mathrm{~N} / \mathrm{mm}^{2}$ at cervical margin on the labial side. It was noticed that the stress pattern interchanged at the center of rotation and compressive stress of $-0.026697 \mathrm{~N} / \mathrm{mm}^{2}$ was seen on labial side and tensile stress of $0.047291 \mathrm{~N} / \mathrm{mm}^{2}$ was seen on lingual side near the apical region (Fig. 4).

Bodily tooth movement: With this force system, the compressive stress produced on the middle of PDL was found to be $0.010038 \mathrm{~N} / \mathrm{mm}^{2}$ and tensile stress along the labial side was found to be $0.012801 \mathrm{~N} / \mathrm{mm}^{2}$. These stresses
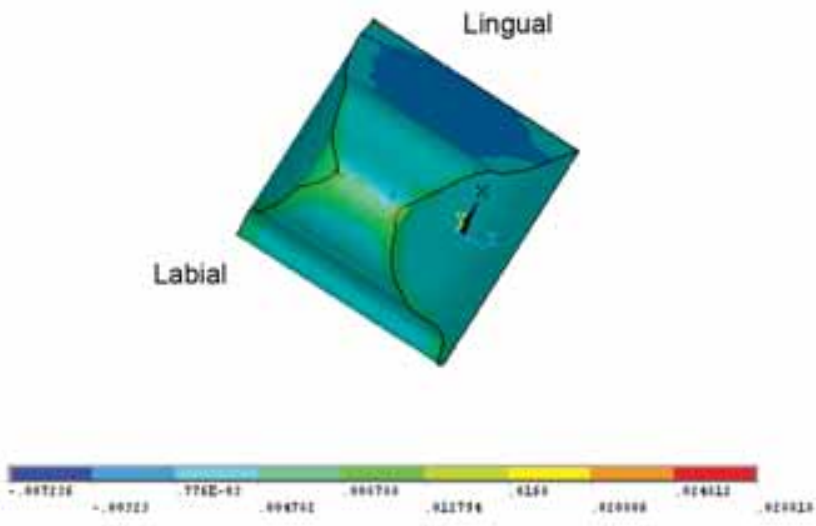

Fig. 3: Stress distribution in PDL during extrusion 
were seen to be distributed throughout the PDL (Fig. 6). The stress concentration at the apical region was found to be $-0.000381536 \mathrm{~N} / \mathrm{mm}^{2}$.

\section{DISCUSSION}

This study investigated the magnitude and stress pattern in the periodontal ligament with emphasis on stress distribution at the apex for different types of tooth movements by means of the finite element method. To carry out the analysis, a maxillary central incisor with its supporting structures was considered.
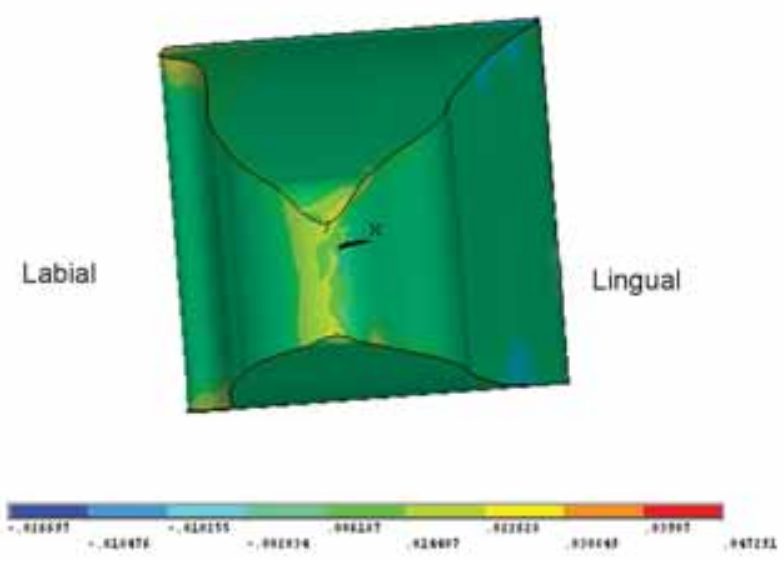

Fig. 4: Stress distribution in PDL during tipping
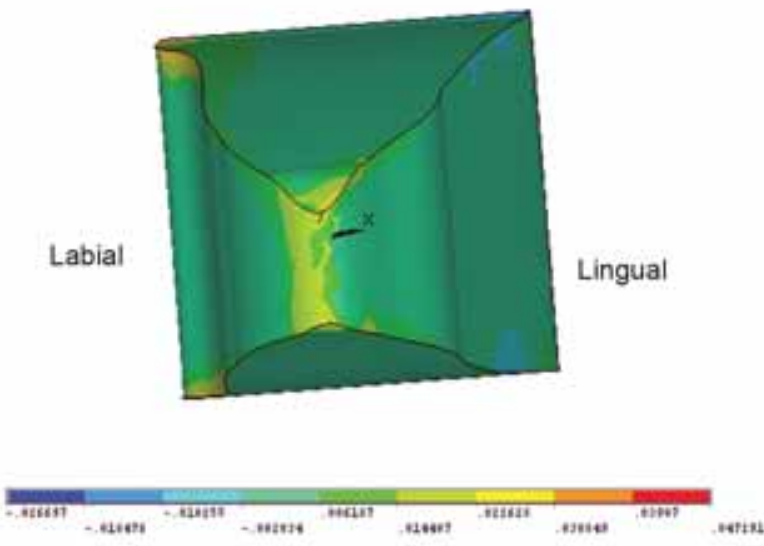

Fig. 5: Stress distribution in PDL during rotation
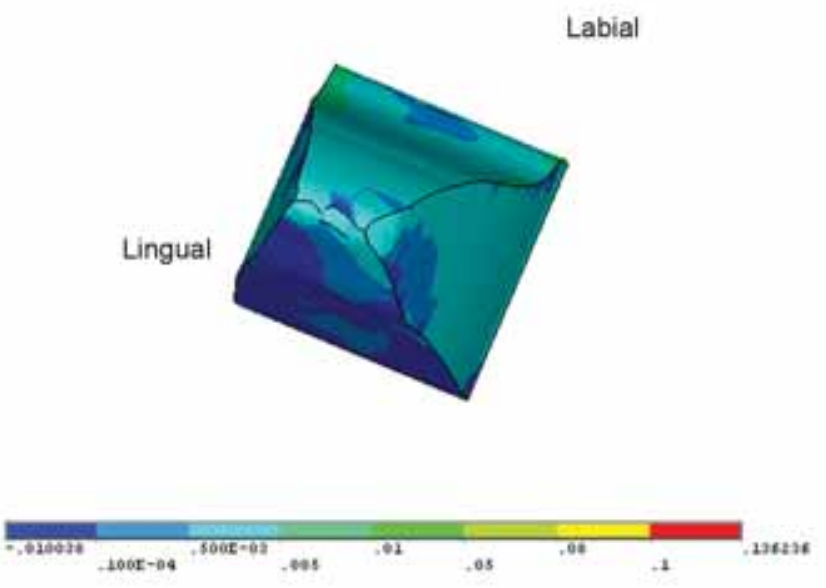

Fig. 6: Stress distribution in PDL during bodily movement
In this present study, stresses were produced with the application of optimal forces as proposed by Profitt ${ }^{9}$ (Table 2). The stresses were found to be low, well below the optimal stress value suggested by Lee. ${ }^{10}$

Intrusion: In the vertical direction, intrusive movement of the teeth has been considered difficult. Attempts at intrusion may result in an increased incidence of root resorption and also in occasional devitalization. The stress distribution is not as might be expected from the clinical observation that is entirely compressive stress for intrusive forces over the whole periodontal ligament. In this study, the stress was found to be mainly concentrated at the apex.

The stress profiles here were similar to other finite element studies conducted. ${ }^{11,4,12}$ It was observed that area of periodontal ligament immediately adjacent to the point of force application comes under tensile stress (Fig. 2). This may be due to the fact that the intrusive force was applied parallel to the long axis on the center of clinical crown and not along the long axis. It was observed that to achieve true vertical intrusion, sufficient torque needs to be applied to carefully control the position of the root apex.

Extrusion: In this present study, the stress distribution is not as might be expected from clinical observation that is entirely tensile stress for extrusive forces over the whole periodontal ligament. Stress was found to be mainly concentrated at the apex. It was mainly tensile in nature. The extrusive forces demonstrated similar stress patterns to that of the intrusive force at the root apex. The stress profiles here were similar to other finite element studies conducted. $^{4,11}$ It was observed that the area of the periodontal ligament immediately adjacent to the point of force application comes under compressive stress (Fig. 3). This maybe due to the fact that the extrusive force was applied parallel to the long axis on the center of clinical crown and not along the long axis. To achieve true extrusion, sufficient torque must be added to carefully control the position of the apex.

Rotation: In this study, the stress was mainly seen to be concentrated at the apex of the tooth. During stress distribution, lack of areas of high mechanical stress on the periodontal ligament was observed. The stress pattern in this present study was found to be similar to the study conducted. ${ }^{4}$

Tipping: In the present study, when tipping force was applied, it was found that stress was mainly concentrated at the cervical margin and the apical region. At the cervical region, compressive stress was seen on the lingual side and tensile stress on the labial side. The stress pattern interchanged at the center of rotation with stress being compressive on the labial side and tensile on the lingual side at the apical region. This study also showed that most of the stresses were concentrated at the crest of the alveolar 
bone and not at the apex. These stress patterns were found to be similar to other finite element studies conducted. ${ }^{3,4,7,12,13}$

Bodily movement: In the present study, a force of $70 \mathrm{gm}$ was applied at the center of the clinical crown in labiopalatal direction. A counterbalancing force of $44.2 \mathrm{gm}$ was applied at the incisal tip in the palatolabial direction. So, the net force applied was $25.8 \mathrm{gm}$ to move the tooth palatally. The stresses were found to be evenly distributed throughout the length of the periodontal ligament, but it was more concentrated at the alveolar crest. The stress patterns and trends were found to be similar to the other finite element studies conducted. ${ }^{4,7,13}$

\section{CONCLUSIONS}

It is clear that different force vectors create different stresses throughout the root:

- The three-dimensional FEM model is useful in analyzing the stress that occurs in and around a tooth in response to orthodontic forces

- The greatest amount of relative stress at the apex of maxillary central incisor occurred with intrusion, extrusion and rotation

- Bodily movement and tipping forces produce stresses concentrated at the alveolar crest and not at the root apex.

The periodontal ligament was considered to be isotropic and elastic. This may not be adequate in future modeling, where bone resorption and tooth movement may take place, when periodontal ligament may need to be considered as a viscoelastic medium. This property of the ligament will need to be built into future studies.

Clinical implications of this study suggest that if the clinician is concerned about placing heavy stresses on the root apex, then vertical and rotational forces must be applied with caution. However, the link between external forces and apical root resorption is not very clear cut. Because of lack of reliable animal model, we simply do not know why similar mechanical forces affect one person so differently from others. It is likely that root resorption is a complex, multifactorial system with biochemical thresholds that vary significantly among individuals. ${ }^{4}$

In the future, it is anticipated that the finite element approach can be integrated with animal and clinical experiments to address key questions, such as optimal stress and the relation of stress to tooth movement and bone remodeling. Finally, it can be concluded that this tridimensional model is a useful example to investigate the biomechanism of dental movement, keeping in mind that it is more valid as a qualitative study.

\section{REFERENCES}

1. Jones ML, Hickman J, Middleton J, Knox J, Volp C. A validated finite element method study of orthodontic tooth movement in human subject. J Orthod Mar 2001;28(1):29-38.
2. Choy K, Pae EK, Park Y, Kim KH, Burstone CJ. Effect of root and bone morphology on the stress distribution in periodontal ligament. Am J Orthod Dentofacial Orthop Jan 2000;117(1): 98-105.

3. Qian H, Chen J, Katona TR. The influence of PDL principle fibres in a three-dimensional analysis of orthodontic tooth movement. Am J Orthod Dentofacial Orthop Sep 2001;120(3): 272-79.

4. Rudolph DJ, Willes PMG, Sameshima GT. A finite element model of apical force distribution from orthodontic tooth movement. Angle Orthod Apr 2001;71(2):127-31.

5. Shaw AM, Sameshima GT, Vu HV. Mechanical stress generated by orthodontic forces on apical root cementum: A finite element model. Orthod Craniofac Res May 2004;7(2):98-107.

6. McGuinness NJ, Wilson AN, Jones ML, Middleton J. A stress analysis under periodontal ligament under various orthodontic loadings. Eur J Orthod June 1991;13(3):231-42.

7. Puente MI, Galbán L, Cobo JM. Initial stress differences between tipping and torque movements. A three-dimensional finite element analysis. Eur J Orthod Aug 1996;18(4):329-39.

8. Wheeler's Dental Anatomy, Physiology and Occlusion (6th ed).

9. Profitt William R, Fields Henry W, Jr. Contemporary Orthodontics (3rd ed).

10. Lee Brian W. Relationship between tooth-movement rate and estimated pressure applied. Journal of Dental Research 1965; 44:1053.

11. Wilson AN, Middleton J, Jones ML, McGuinness NJ. The finite element analysis of stress in the periodontal ligament when subject to vertical orthodontic forces. Br J Orthod May 1994; 21(2):161-67.

12. Geramy Allahyar. Initial stress produced in the periodontal membrane by orthodontic loads in the presence of varying loss of alveolar bone: A three-dimensional finite element analysis. Eur J Orthod Feb 2002;24(1):21-33.

13. Tanne K, Sakuda M, Burstone CJ. Three-dimensional finite element analysis for stress in the periodontal tissue by orthodontic forces. Am J Orthod Dentofacial Orthop Dec 1987;92(6):499-505.

\section{ABOUT THE AUTHORS}

\section{Anirudh K Mathur \\ (Corresponding Author)}

Assistant Professor, Department of Orthodontics, HKDET Dental College, Humnabad, Karnataka, India, Phone: +91-9866166400 e-mail: dranirudhkm@yahoo.co.in

\section{Vikas Gupta}

Assistant Professor, Department of Orthodontics, JCDV Dental College, Sirsa, Haryana, India

\section{Anirban Sarmah}

Chief Orthodontist, Department of Orthodontics, New Dental Clinic Jorhat, Assam, India

\section{Vinaya S Pai}

Professor and Head, Department of Orthodontics, Bangalore Institute of Dental Sciences, Bengaluru, Karnataka, India

\section{G Chandrashekar}

Professor and Head, Department of Orthodontics, Pannaneeya Dental College, Hyderabad, Andhra Pradesh, India 